\title{
Del espacio geográfico al turismo como uso y disfrute del territorio comarcal: una reflexión teórica desde España ${ }^{1}$
}

\author{
Félix Pillet Capdepón²
}

\begin{abstract}
RESUMEN
Los momentos de crisis que estamos viviendo nos obligan a replantear la situación en las distintas escalas del espacio geográfico, sin olvidar la preocupación por la relación espacio-tiempo. Una de las temáticas de estudio de mayor interés geográfico, actualmente, es el turismo, por dos razones: por convertir al territorio en recurso y factor al mismo tiempo, y la segunda por ser un sector claramente competitivo. Por este motivo su análisis se desarrollará, analizando la evolución del paisaje literario a partir de la literatura de viajes, como precedente turístico y, a continuación, se estudiarán los espacios del turismo en España, con el fin de plantear el interés turístico del patrimonio territorial o comarcal.
\end{abstract}

Palabras clave: Espacio geográfico, Paisaje literario, Turismo, Patrimonio territorial.

\begin{abstract}
The current crisis obliges us to rethink the situation at the different scales of geographic space, without forgetting the space-time relationship. Nowadays, a topic of great geographic interest is tourism. The interest is two-fold: 1) due to the fact that territory has become a resource and a factor at the same time, and 2) because it is an sector that is clearly competitive. For these reasons, this analysis will be developed starting from the evolution of the literary landscape, beginning with travel books and touristic precedent, and continuing with and analysis of tourism spaces in Spain, with the aim of fomenting touristic interest in territorial or local heritage.
\end{abstract}

Key words: Geographical space, Literary landscape, Tourism, Territorial heritage

\footnotetext{
1 Artículo recibido el 15 de noviembre de 2014 aceptado el 27 de abril de 2015 y corregido el 10 de junio de 2015.
}

\footnotetext{
2 Universidad de Castilla-La Mancha (España). E-mail: Felix.Pillet@uclm.es
} 
El eclecticismo geográfico actual parte de las aportaciones de las distintas acepciones del espacio geográfico ${ }^{3}$ para dar respuesta a sus diversas escalas, pasando con el desarrollo de la globalización, de la dicotomía global-local o "glocalización" a una visión más real y escalar: el espacio desde lo global a lo local que proponía Sara González en 2005 (Pillet, 2008: 58). Dicho eclecticismo ha dejado a un lado la sucesión de paradigmas, que concluyó con el posmodernismo, para centrarse en el objeto de estudio: el espacio, y más concretamente, el territorio, pero también, la necesaria relación espacio-tiempo, así como la profundización de las distintas temáticas de trabajo e investigación. Estas se concretan en la actualidad en la problemática ambiental, en la relación espacio-poder, en la conexión urbano-rural, así como en otros aspectos, donde el turismo ocupa un lugar muy destacado pues el territorio se convierte en recurso y factor, en producto de consumo cultural.

El posmodernismo ha puesto su atención en diversos aspectos: los giros o cambios geográficos, el redescubrimiento del sujeto/ individuo, la perspectiva cultural y una nueva espacialización de las Ciencias Sociales (Lindon y Hiernaux, 2010). Junto a esta última corriente de pensamiento, el eclecticismo reinante debe saber mirar el futuro del espacio social con imaginación, combinando la teoría con la práctica, lo que obliga a un necesario "camino teórico-metodológico" (Carlos, 2012), con el fin de aunar los distintos lenguajes geográficos.

La necesaria insistencia en los planteamientos teóricos, en la unidad de la Geografía, en la internacionalización de la investigación geográfica (García Ruiz, 2008), cobra cada día mayor trascendencia. La Geografía española ha realizado un balance de su investigación dada la diversidad temática, la creciente complejidad metodológica y la variedad de herramientas que se vienen empleando. Llama la atención que junto a las áreas geográficas de trabajo, se incorpore también la investigación realizada por geó-

\footnotetext{
3 El espacio concreto o regional (posibilismo), el espacio abstracto (empírico-analítico), el espacio subjetivo (histórico-hermenéutico), el espacio social (crítico) y el espacio global-local (Pillet, 2008).
}

grafos extranjeros en nuestro país, y especialmente la producción científica de la geografía española en Iberoamérica (Lasanta y Martín Vide, 2013). Este último aspecto ha sido tratado contemplando la presencia de la geografía iberoamericana en las revistas científicas españolas, debido a la proximidad histórica y cultural (García et al., 2009).

\section{El espacio: escalas y tiempos}

La estructura escalar del espacio (escala planetaria o global, continental y/o supranacional, estatal-subestatal, y local) ha sufrido en la primera, la planetaria, cambios importantes desde 2008 como consecuencia de la crisis financiera-inmobiliaria del neocapitalismo. De hecho la Ilamada "tríada global" que estaba representada por la cúspide del poder mundial: Estados Unidos, Japón y la Unión Europea, se encuentra en proceso de estancamiento; nuevos países emergentes o BRICS (Brasil, Rusia, India, China y Sudáfrica), este último en menor medida, han venido a poner en cuestión el statu quo. De esta forma, la jerarquía mundial la ocupan de forma paralela dos países: Estados Unidos en desarrollo económico y China en crecimiento. Estamos presenciado, en la actual desigualdad social, la consolidación de tres nuevos mundos de la economía: el desarrollado, con problemas de estancamiento; el emergente en crecimiento, y por último, el mundo de la pobreza y/o la hambruna. Durante el año 2015 los países emergentes están ofreciendo un fuerte descenso en su crecimiento.

La segunda escala, la continental, ofrece como único ejemplo de supranacionalidad a la Unión Europea, a la espera de otras agrupaciones consistentes. La Unión nació con una doble propuesta de cohesión: social y económica (Tratado de Maastricht, 1992), a las que siguió la cohesión territorial (Tratado de Lisboa, 2007). Objetivo este último que, en teoría, pretende que la riqueza llegue a todos los rincones de Europa mediante un desarrollo equilibrado, sostenible y policéntrico, siendo el eje vertebrador del policentrismo la red de ciudades o centros capaces de organizar a su alrededor auténticas Áreas Funcionales Urbanas (FUAS) tal y como se contempla en la Estrategia Territorial Europea (ETE). El policentrismo viene interesando a los investigadores de otros continentes, como es el 
caso de América Latina (Maturana y Arenas, 2012). El concepto de cohesión ha cobrado fuerza durante la última década, siendo una de las expresiones más citadas en el ámbito de las políticas territoriales (Fernández et al., 2009). Pero la crisis ha sometido a la Unión a un aletargamiento, a un estancamiento que la incapacita como modelo, no solo territorial sino también de reactivación económica.

El Estado y su división administrativa interna o Subestado se convierten en la tercera escala. La necesidad de ahorro en inversión pública ha originado que uno de los países menos descentralizados como es Francia haya llevado a cabo, por razones estrictamente económicas, la reducción de sus regiones: de 22 a 13 en 2014, al tiempo que se anuncia para un futuro la eliminación de las provincias, la reducción de mancomunidades y la reagrupación de los municipios ${ }^{4}$. España, país más descentralizado que la Alemania federal, ha visto cómo el endeudamiento de sus Comunidades Autónomas se ha convertido en un gran problema (Castaño, 2011), pero a pesar de ello no existe ningún pronunciamiento oficial tendente a reordenar desde el gobierno del Estado su estructura territorial. Se siguen manteniendo, constitucionalmente, las provincias heredadas del pasado con sus diputaciones (Burgueño, 2011), cuando parece lógico que se debía haber potenciado una nueva ordenación de las Comunidades Autónomas, tomando como base la ETE (Ureña et al., 2013). Se echa en falta una reordenación o agrupación municipal, ya que más del $70 \%$ de los 8.116 municipios $^{5}$ registran menos de dos mil habitantes, los denominados rurales, lo que los convierte en entidades con escasa funcionalidad y elevada fragmentación (Burgueño y Guerrero, 2014). La nueva Ley de Racionalidad y Sostenibilidad de la Administración Local, de diciembre de 2013, se limita a posibilitar "incentivos a la fusión voluntaria"6, en lugar de animar a las Comunidades Autónomas a emprender el ne-

4 Diario El País, 3 de agosto de 2014.

5 Chile, por ejemplo, cuenta solo con 346 municipios comunas, cuando la estructura territorial restante es similar a España: 15 regiones y 54 provincias.

6 http://www.seap.minhap.gob.es/dms/es/servicios/retribuciones_CCAA_CCLL/ISPA-2014/BOEA-2013-13756.pdf cesario proceso de reagrupación municipal. El endeudamiento sufrido debe ser acicate suficiente para reformar el Estado de las Autonomías, eliminando obstáculos como las diputaciones provinciales, así como convertir el Senado en Cámara Territorial o suprimirlo; o bien optar por el Estado Federal, que se viene defendiendo desde dos partidos de izquierda.

La escala local o el interior del Subestado $^{7}$, no solo es el ámbito oficial de la planificación, sino también el terreno de la investigación en Ciencias Sociales y más concretamente en Geografía. Debido a la fragmentación municipal se hace cada vez más imprescindible, junto a la reagrupación de los pequeños municipios, potenciar la escala supramunicipal "porque en estos niveles es donde está la gran carencia de la planificación territorial española" (Zoido, 2010: 96). Existen dos formas de agrupación supramunicipal del total de los municipios ${ }^{8}$, una más funcional, que se fundamenta en el Policentrismo y en las Áreas Funcionales (antiguas comarcas funcionales), y en definitiva en la cohesión territorial (Pillet et al., 2014); y la otra más cultural, paisajística y turística, que hace referencia a las comarcas geográficas. Junto a los territorios mencionados tenemos que unir el papel perceptual del paisaje, interpretado en el Convenio Europeo del Paisaje (2000) ${ }^{9}$ que lo define como "cualquier parte del territorio tal como lo percibe la población, cuyo carácter sea el resultado de la acción y la interacción de los factores naturales y/o humanos"10.

Si la escala de estudio es fundamental a la hora de analizar una temática (natural, rural, urbana... turística), no lo es menos el proceso seguido a lo largo del tiempo, o lo que es lo mismo la relación espacio-tiempo. Desde las últimas décadas, las investigaciones están dejando a un lado la utilización de los archivos, de las fuentes históricas, para el análisis del devenir del territorio, lo que lleva consigo el

\footnotetext{
7 En el caso de España lo representan las Comunidades Autónomas.

8 Los Territorios LEADER y las Mancomunidades excluyen los municipios urbanos e industriales

9 Ratificado por el Reino de España en 2008.

10 http://gl.www.mcu.es/patrimonio/docs/Convenio_europeo_paisaje.pdf
} 
olvido del pasado, de la Geografía histórica y crítica que reivindica Harvey (2007). Por este motivo nos interesa el debate o cruce de opiniones que se ha establecido sobre la relación tiempo y espacio, dada la dificultad que tiene la Geografía para explicar procesos temporales o los imaginarios geográficos del pasado (Mendizábal, 2013; Zusman, 2013). Se ha afirmado que "el período produce un medio geográfico y el medio geográfico lo es de un determinado período" para añadir con total contundencia que "los estudios geográficos podrán ofrecer una interpretación crítica del mundo si aceptan el desafío de aprehender la temporalidad del espacio y la empiricidad del tiempo" (Silveira, 2013: 24 y 26), empirización que se alcanza por medio de la periodización ${ }^{11}$.

A los aspectos citados: las escalas del espacio y los tiempos, nos queda por último añadir la temática de estudio que ya avanzamos anteriormente, que sería el turismo. Parece lógico que antes de analizar un aspecto concreto de los espacios del turismo, como es el caso del interés del territorio comarcal como objeto de interés turístico, se analice el precedente turístico que encontramos en los distintos tipos de viajeros por el mundo, tomando como referencia la literatura de viajes, pues existe un turismo actual que se viene identificando con el viejo ideal romántico del viaje.

\section{Los viajeros y los paisajes literarios}

Alexander von Humboldt, gran viajero, inició la preocupación por la consideración de las imágenes de la naturaleza y del paisaje, que luego continuarían los escritores y viajeros románticos, conformando la imagen literaria moderna del paisaje (Ortega Cantero, 2003: 30-32). Por aquellos años, el "Grand Tour" y el "Tour Romántico" se convirtieron en el precedente del turismo, pero la literatura de viajes tiene un origen anterior. Por este motivo parece lógico que se puedan establecer tres etapas que vienen a aclarar dicha

\footnotetext{
${ }^{11}$ Se ha desarrollado utilizando como ejemplo la evolución de la propiedad en las distintas escalas del territorio español (Pillet, 2012 a).
}

evolución: el viaje como saber estratégico, formativo y estético.

\section{El viaje como saber estratégico}

A partir de distintos ejemplos que tuvieron su punto de partida en los países que bordean el Mediterráneo se comprobará cómo, con el paso del tiempo, el factor distancia irá desarrollando nuevas escalas con objeto de descubrir y colonizar territorios, tanto continentales, como transoceánicos. El inicio del saber estratégico lo situaremos en el siglo V antes de Cristo con las "Historias" de Heródoto de Halicarnaso, en su recorrido por Egipto, Asia Menor, Babilonia, etc. Él convirtió a Egipto en un país de especial admiración: "qué poder tiene el Nilo para que naturalmente se comporte al revés de los otros ríos. Yo preguntaba con la intención de saber lo que acabo de decir y también por qué el Nilo es el único río que no da lugar a la formación de brisas" (Heródoto, 1990, II, 19). Se ha dicho que fue agente de información del imperio ateniense (Lacoste, 1977), y que "el libro de Heródoto es el primer gran reportaje de la literatura universal" (Kapuscinski, 2006: 291). Unos siglos después, también en Grecia, Estrabón (siglo I después de Cristo), recogió en su obra "Geografía" su viaje hasta la India, aprovechando la paz romana. Describió las diferentes regiones del mundo conocido (ecumene), iniciando el recorrido por la Península Ibérica: "De esta, la mayor parte es difícilmente habitable, pues en gran extensión la pueblan montañas, bosques y llanuras de suelo pobre que ni siquiera disfruta del agua uniformemente". Una situación más favorable la encuentra en la zona meridional (Andalucía) "en cambio la del sur es casi en su totalidad fértil", para a continuación indicar que "Iberia se asemeja a una piel de buey extendida a lo largo de Oeste a Este" (Estrabón, 1991: 33-35). Se puede constatar, que los grandes viajeros griegos nos enseñaron una metodología de reflexión muy valiosa, pues su aportación fue pura y simple literatura que gozaba de una enorme popularidad (Gómez Espelosin, 2000).

Con el auge de las ciudades medievales, la literatura de viajes recogió la aportación de Marco Polo e Ibn Batuta. Ambos, cristiano y musulmán, respectivamente, Ilegarían a China, utilizando los dos a su vuelta un 
escribiente para redactar sus obras. Marco Polo llevó a cabo sus viajes desde Venecia, pasando por Armenia, Arabia, Persia, Tartaria, India, para terminar en China. En su obra "El libro de las cosas maravillosas" habla de las religiones y culturas; de las provincias y reinos; de las ciudades y villas; de los buenos pastos y dehesas, de los ríos y desiertos, y de su larga estancia en la India: "vi la India mayor e menor... moré gran tiempo" (Polo, 2004). Ibn Battuta nos presenta en "A través del Islam", traducción española de la Rihla, su viaje desde Tánger (1325) volviendo a Marruecos en 1353 después de haber recorrido la peregrinación de La Meca, la India y China. La Meca es "una gran ciudad, de construcciones apiñadas". En la India se fija en los cultivos de huerta, especialmente en el mango. Y por último su admiración por China

"La China es un territorio inmenso, con toda clase de productos, frutos, cereales, oro y plata. Ninguna otra tierra se le puede comparar... cuantas frutas hay en nuestros países se encuentran en China aún mejores. Igualmente abundan en trigo y jamás vi otro de mejor calidad" (Ibn Battuta, 1981: 224, 449 y 720).

En la introducción a la obra, Fanjul y Arbós cuando se refieren al viaje señalan que pretende "ser útil e informar lo más minuciosamente posible sobre todo lo visto" ofreciendo un cuadro bastante correcto del mundo musulmán, así como de otros países visitados. Narró las costumbres, los sucesos y acontecimientos, exagerando en bastantes ocasiones los sucesos, existiendo a veces contradicciones entre la realidad y la fantasía. Obra resultado de su excelente memoria y buenas dotes de observación.

Terminaremos esta etapa con el viajero que viene a cerrar el ciclo del conocimiento y conquista del Nuevo Mundo. El genovés Cristóbal Colón quería Ilegar a China siguiendo los pasos de Marco Polo, navegando por el Atlántico y pasando por Canarias. Debido a un cálculo erróneo de las distancias, descubriría el Nuevo Mundo. Si el primer viaje tuvo como misión oficial lo puramente comercial, lo económico; el segundo viaje, conscientes de haber conquistado el Nuevo Mundo, la misión era triple: conquistadora, colonizadora y evangelizadora. A los cuatro viajes se unió su enfermedad, lo que dio paso a la firma de su testamento en Valladolid (1506), muriendo ese mismo año, en él se puede leer que fue el conquistador de "tierra firme de las Indias descubiertas e por descubrir" (Colón, 1986: 297). Otros contemporáneos suyos continuarían su labor por el nuevo continente.

\section{El viaje como saber formativo y científico}

Desde finales del siglo XVI los viajes por Europa se desarrollaron realizando los trayectos en carro, en caballo de silla, en coche y especialmente en diligencia, portando los viajeros pasaporte o visado, así como la necesidad de ir armados, en algunas ocasiones. Un destino muy destacado fue Roma, seguido de París y Londres. Uno de los primeros ejemplos lo tenemos con Michel de Montaigne que decidió, como tantos otros, viajar a Italia saliendo desde Burdeos, pasando por Suiza y Alemania. En su obra "Diario de viaje a Italia" (1580-81) va recorriendo todas las ciudades, aldeas y caseríos que aparecen en el camino, se preocupa en buscar los manantiales de aguas y los balnearios, lo que indica su interés por la salud. La única ciudad que parece preocuparle y de hecho se detiene para saborearla es Roma:

"La ciudad está, en la actualidad, totalmente edificada a lo largo del Tiber, a uno y otro lado. El barrio alto, que era la sede de la ciudad antigua... está ocupado por algunas iglesias, mansiones singulares y jardines de cardenales... Roma no llega a un tercio del tamaño de París; en número y dimensiones de las plazas publicas, y en belleza de calles y casas, Roma la supera con mucho" (De Montaigne, 2010: 200-244).

Esta obra sirvió de precedente de lo que se conoció como "Grand Tour", acontecimiento que afectó a los viajeros europeos (ingleses, franceses y alemanes) interesados en el conocimiento de las ciudades más importantes, especialmente de Italia, donde pretendían hacer un seguimiento de las artes y las antigüedades, de las ciencias de la naturaleza, del conocimiento del país, con la posibilidad de asistir a tertulias donde poder intercambiar opiniones, fue "una experiencia que solo pueden permitirse los más ricos o los más audaces", es decir, la aristocracia o 
la incipiente burguesía resultante de la revolución industrial (Lledó, 2000: 129). Lo que favoreció esta nueva situación, fue por un lado, la presencia de párrocos ingleses, con formación universitaria, pues algunos de ellos se convirtieron en preceptores y tutores de jóvenes de la nobleza; y por otro, un sistema más seguro de "transferencia de dinero y de créditos", que favorecieron los desplazamientos (Maczak, 1996: 234). Uno de los viajeros más representativos fue el poeta alemán Johann W. Goethe, que en su obra "Viaje a Italia" en 1786-88, aunque publicada posteriormente (1816), recoge su experiencia por distintas ciudades de norte a sur, para concluir en el Vesubio y en Sicilia "granero de Italia... uno de los países más fértiles de la tierra". Si la primera parte es un canto a la herencia arquitectónica y a la civilización grecolatina, la segunda es una exaltación de la naturaleza:

"salía del Vesubio fuerte lava, tomando el camino del mar. Casi había bajado ya las cuestas más escabrosas de la montaña, y llegaría á la orilla... Todo hubiera estado muy bien si la lava no se hubiera ocupado de mi imaginación... Allí vi todos los fuegos y las luces y su resplandor, más oscilante porque la mar estaba más movida" (Goethe, 1891: II, 99-101).

España quedó al margen del "Grand Tour" debido a la leyenda negra ${ }^{12}$, pero serán los visitantes de finales del siglo XVIII los que tratarán de romper los tópicos legendarios, nos referimos a Tonwnsend (1786-87) y Bourgoing (1789), especialmente, siendo este último el que realizó una aproximación más objetiva (Ortás, 2005). No solo algunas ciudades y balnearios se convirtieron en lugares preferidos, también la montaña apareció como destino viajero para los ilustrados, cuando anteriormente se contorneaba (Moureau, 2005).

Entre finales del siglo XVIII y comienzos del siglo XIX nos encontramos con los viajes de dos naturalistas: Humboldt y Darwin. La

\footnotetext{
12 Opinión contra lo español difundida a partir del siglo XVI, especialmente desde Inglaterra, que duraría hasta la segunda parte del siglo XVIII o incluso hasta la Guerra de la Independencia contra los franceses.
}

obra de Alexander von Humboldt: "Viaje a las regiones equinocciales del nuevo continente", se iniciaría en España, y su publicación se llevó a cabo entre 1808 y 1834, en el prefacio señalará el autor que "viaja con fines científicos". Un paraje singular sería el situado entre los valles de Aragua y los llanos de Caracas, donde nos presenta por primera vez una imagen real de la naturaleza, en contacto con el hombre:

"La montaña de estas estepas tiene algo de grandioso, pero también de triste y opresivo... Los Ilanos o pampas americanos son verdaderas estepas. En la estación Iluviosa tienen un hermoso verde, y en las más secas adquieren el aspecto de desiertos. La hierba se descompone y reduce a polvo; el suelo se agrieta" (Humboldt, 1962: 168).

Considerado como "el descubridor científico de América", su aportación representó el punto final de la investigación enciclopedista de la Ilustración (Rebok y Fernández, 2006). Por su parte, Charles R. Darwin Ilevó a cabo una importante travesía marítima: "Viaje de un naturalista alrededor del mundo" (183135), estudió la historia natural de distintos países, partió de Inglaterra, y recorrió la costa occidental y oriental de América Latina, Nueva Zelanda, sur de Australia y de África. Observó las distintas etapas geológicas, la flora, la fauna, los fósiles y la relación del hombre con otras especies. De su obra extraemos la siguiente reflexión:

"Entre los cuadros que más honda impresión han causado en mi espíritu, ninguno tan sublime como el aspecto de las selvas vírgenes donde no hay ni vestigios del paso del hombre; sean éstas las de Brasil, donde domina la vida en toda su exuberancia... Las Ilanuras de la Patagonia son ilimitadas, apenas pueden atravesarse; por eso son tan desconocidas... Queda señalar desde el punto de vista pintoresco, el panorama que se desarrolla a los pies del viajero situado en la cima de una montaña elevada" (Darwin, 1989: 448-450).

\section{El viaje como placer estético}

A los viajeros ilustrados del "Grand Tour" se unieron los viajeros románticos, también 
Ilamado Tour Romántico, pero en esta ocasión ya no se viaja por conocer o ilustrarse sino por puro placer, por entretenimiento, por un afán decadente, melancólico y estético. Un lugar destacado de destino lo ocupó España. De todos los viajeros, no cabe duda que Richard Ford fue quien ha ejercido una mayor influencia con su "Manual para viajeros por España" (1845). Ford destacó a este país como "el más romántico y característico de Europa", ocupando un lugar muy especial Andalucía, pues allí convive el occidente con el oriente, el paisaje aparece transido de subjetividad y de pretensiones estéticas, mostrando una concepción "oriental" (López Ontiveros, 2001). Tras señalar los distintos tipos y maneras de viajar, indicará que el clima del país es muy desigual, la península es "una montaña o aglomeración de montañas... siete cadenas distintas de montañas". Si los románticos buscaban países montañosos y ciudades con encanto, estas entrarán dentro de la siguiente recomendación, comenzando lógicamente por Andalucía: "Los principales puntos de interés de la Península son Andalucía, Madrid, donde hay que incluir Toledo, Ávila, Salamanca..." (Ford, 2008, I: 185).

De la subjetividad de los románticos pasaremos a la crónica social de viaje. Ahora a los recorridos a pie, en carruaje y por primera vez en tren, citaremos como mejor ejemplo a Charles Dickens con su obra "El viajero sin propósito" (1860-1870) en la que nos Ileva por Europa: Inglaterra, Francia, Suiza e Italia. Describe con humor sagaz cuantos acontecimientos va viviendo, especialmente cuando asciende "por los desfiladeros de los Alpes":

"Así que yo subía y subía las cuestas a paso lento y pesado... se disipaba la niebla, y aparecía un paisaje de pueblecitos pintorescos... Entraba en ellos y me paseaba por los mercados y por el laberinto de calles empinadas... mujeres con bocios tan enormes que se hacía difícil discernir donde terminaba la madre lactante y donde empezaba el niño..." (Dickens, 2014: 41).

Durante las primeras décadas del siglo $X X$ dos ciudades se convierten en centro de atención, por un lado París "ciudad de la luz" que atrajo el interés de buen número de viajeros estadounidenses, debido a la bohemia, al sentido de libertad y a los bajos precios, como afirma Leguineche en el prólogo de una de las obras, de los viajeros más significativos, nos referimos a Ernest Hemingway, que la habitó entre 1921 a 1926, experiencia que fue publicada más tarde (1960): "París era una fiesta". En la obra hará su particular defensa del río Sena: "en las corrientes y remolinos que el Sena forma al fluir se encuentran excelentes puntos de pesca". Para terminar afirmando: "París no se acaba nunca... siempre valía la pena". La otra ciudad sería Nueva York a la que Ilegaron, entre otros, distintos escritores españoles, como Juan Ramón Jiménez, José Moreno Villa, Federico García Lorca y Julio Camba (Pillet, 2015a), ellos ayudaron en sus escritos a comprender mejor el rápido cambio morfológico de la ciudad. A Julio Camba se le conoce como un escritor viajero, corresponsal de periódicos por grandes capitales: París, Roma, Londres, Ginebra, Berlín y Nueva York. Ofreció una imagen distinta de la realidad, pues pone su atención en lo cotidiano y corriente, y no en lo exótico. Nueva York aparece como "una civilización distinta a las civilizaciones del viejo mundo", pues a ella llegó en dos ocasiones para trabajar (1916 y 1931). A las prisas que observó en un primer momento se añade la siguiente impresión: "Es una ciudad delirante, una ciudad exasperada y frenética... es la ciudad más plástica del mundo" (Camba, 2014: 328 y 329).

Desde mediados del siglo XX, uno de los viajeros más destacados fue el norteamericano Paul Bowles, compositor de música, novelista y poeta. En su libro: "Desafío a la identidad. Viajes 1950-1993" ofrece un amplio recorrido por París, Costa del Sol, Tailandia, Kenia Estambul, Madeira, India, y muy especialmente por Marruecos. Advertirá que los libros de viajes no solo son del gusto de los aventureros y de los que no viajan, sino que además señalará que el relato debe ceñirse lo más posible a la realidad. Cuando habla de Marruecos y concretamente de Tánger indicará que es "una ciudad atractiva y tranquila, con unos sesenta mil habitantes... lugar fascinante para el forastero que tenga el tiempo y la inclinación de conocer a su gente". En uno de los textos, titulado "Bautismo de soledad" aparece esta visión del desierto del Sahara:

"Al instante en que uno llega al Sahara, por primera o décima vez, se percata de 
la quietud. Un silencio increíble y absoluto... el aire tiene una cualidad de callado como si la quietud fuese una fuerza consciente que, molesta con la intrusión del sonido, lo minimiza y lo dispersa en el acto. Después está el cielo, frente al que todos los demás cielos parecen tímidos esfuerzos" (Bowles, 2013: 388).

A los viajeros seleccionados, entre otros muchos, parece conveniente recoger, para terminar este apartado, dos reflexiones, la primera del italiano Claudio Magris donde en su infinito viajar afirma que

"A veces es como si el viajero resurgiera del agujero negro de su personalidad y se quedase casi sorprendido de la dirección en la que le llevan sus pasos, revelándole patrias del corazón antes desconocidas para él. Le voyage, dijo un loco parisino, pour connaître ma géographie" (Magris, 2008: 31).

Luis y Alexis Racionero, como resultado del ansia de vagar, distinguen el viajero de toda la vida, del turista actual, cuando señalan que la diferencia no solo pertenece a la literatura sino que está basada en hechos "La distinción entre viajero y turista no es solo literaria sino factual... El viajero reposa, el turista corre" (Racionero, 2013: 14 y 15).

\section{De los espacios del turismo al patrimonio territorial o comarcal en España}

El proceso turístico seguido en Europa ha variado según los países, su inicio data de los años cuarenta del siglo XIX, cuando Thomas Cook creó la primera agencia de viajes organizados, tras el "Grand Tour" y especialmente, el "Tour Romántico". El inicio del turismo en España fue más tardío, su evolución se ha dividido en tres etapas: la primera, desde comienzos del siglo $X X$, dio lugar al turismo de élite o prototurismo, centrada en los balnearios. La segunda etapa, desde los años sesenta, se desarrolla con el turismo de sol y playa o turismo fordista. Y la tercera etapa, desde los años noventa, el turismo de interior, coincidiendo con la postmodernidad. El turismo actual se ha identificado con el turismo del patrimonio (heritage tourism) como sinónimo del turismo cultural, pues toda manifestación turística es en esencia cultural volviendo a mirar al ideal romántico del viaje, pues de hecho "la posmodernidad desdibuja las fronteras... entre viajeros y turistas" tal y como ha señalado Donaire (2012: 13), motivo por el que se ha recordado la literatura viajera.

Aunque es cierto que la escala planetaria es determinante para estudiar las prácticas turísticas con el fin de explicar los desplazamientos vacacionales (Lois, 2008: 24), la actual crisis económica ha demostrado que el sector más pujante en España es sin duda el turismo, pues se presenta hoy como el más competitivo del mundo ${ }^{13}$, aunque no se debe caer en la autocomplacencia (Crotti, 2015). Fue a partir de la década de los noventa del siglo XX cuando comenzó en España una política nacional de planificación turística ${ }^{14}$, dirigida a incrementar la competitividad, la dinamización, la calidad y la sostenibilidad (Almeida, 2012). Al turismo de costa se unió el turismo de interior, que tuvo como principal impulso la iniciativa europea LEADER. En la actualidad el Plan Nacional e Integral del Turismo (2012-2015) ${ }^{15}$ viene a demandar a los gobiernos de las Comunidades Autónomas que en sus Planes Estratégicos potencien "experiencias diferenciadas" de interior, basadas en la calidad y en el patrimonio cultural, natural y enogastronómico.

Antes de pasar al estudio de la diversidad de los espacios del turismo, que es una de las temáticas de mayor interés geográfico, se hará una valoración de la investigación desde la Geografía del Turismo, en un intento de aunar la excesiva diversificación temática con la definición metodológica (Fernández et al., 2010), donde sobresalen como aspectos

\footnotetext{
${ }^{13}$ En España se celebran anualmente la Feria Internacional del Turismo (FITUR) en Madrid y la Feria Internacional del Turismo de Interior (INTUR) en Valladolid. Según el diario El País (4 y 7 de mayo de 2015), la cifra de turistas ha alcanzado por primera vez los 65 millones "España tiene el sector turístico más competitivo del mundo" según el Fondo Económico Mundial.

14 I y II Plan Marco de Competitividad del Turismo Español (Futures 1992-99), Plan Integral de Calidad del Turismo Español (PICTE 2000-06), y Plan del Turismo Español Horizonte 2020 (2007-20).

15 http://www.minetur.gob.es/turismo/es-es/documents/ pnit_2012_2015_v2.pdf
} 
más analizados: los usos y actividades desplegadas, el estudio de la diversidad de los espacios turísticos, concretado en la especificidad de las distintas tipologías, y en tercer lugar, la gestión del espacio turístico (Corral y San Eugenio, 2013). Por su parte, en el conjunto de las Ciencias Sociales existen varias revistas especializadas en turismo ${ }^{16}$ (Corral y Cànoves, 2013), a las que se une una amplia investigación científica (Moreno y Picazo, 2012), así como un buen número de tesis doctorales (Ortega et al., 2013).

Investigaciones publicadas en otros países, vienen a ofrecer planteamientos ontológicos, epistemológicos y metodológicos sobre turismo (Phillimore \& Goodson, 2004); un texto que merece ser destacado es el de John Tribe por su evidente carga teórica, en él se señalan los problemas epistemológicos en la investigación del turismo. Se afirma que el turismo no puede ser considerado como una disciplina, pues más bien responde al concepto de "campo" o mejor aún "un conocimiento multidisciplinar" donde cada disciplina proporciona una metodología, lo que origina que los estudios de turismo se sitúen en un estado preparadigmático. Cada campo del turismo constituye en sí mismo un paradigma, donde cada disciplina nos ofrece un escenario propio que ilumina ciertas partes del ámbito del turismo, Ilegando a la conclusión, por tanto, que "el mundo académico ha pasado por alto el modelo de producción del conocimiento" (Tribe, 2004: 50 y 58). En otra obra de recopilación de textos se analizan los principales métodos de investigación que son utilizados por los investigadores del turismo: cuantitativo, cualitativo y mixto (Dwyer et al., 2012). La aportación de Jennings se centra en la dualidad: investigación cuantitativa, relacionada con el enfoque etic (phon-etic), junto a la investigación cualitativa (phonemic). Sobre esta última, que es la que nos interesa, indicará que es un enfoque consolidado que está ganando mayor aceptación en las primeras décadas del siglo XXI, a la vez

\footnotetext{
16 Las revistas de turismo de mayor interés incluidas en la base de datos ISOC son: una geográfica (Cuadernos de Turismo), tres económicas (Estudios Turísticos, Papers de Turismo, y Revista de Análisis Turístico), una antropológica (Pasos) y una sociológica en español (Annals of Tourism Research).
}

que valora positivamente el reconocimiento de la subjetividad del investigador dentro de los procesos de investigación, especialmente cuando se aportan experiencias de fondo (Jennings, 2012).

Los espacios del turismo es uno de los aspectos que sobresalen en las obras de referencia en España (Vera, 2011), por ser una de las temáticas de mayor interés geográfico (Figura $\mathrm{N}^{\circ} 1$ ). El "turismo de costa" viene desarrollándose desde los años sesenta, a él se deben los mayores beneficios económicos pero también los mayores perjuicios al medio ambiente y al paisaje, como consecuencia de la utilización masiva del territorio. Durante los años de la burbuja inmobiliaria se ha producido una fuerte dualidad, pues al dominio del alojamiento hotelero, controlado por los tour-operadores, se ha unido la amplia oferta de viviendas en alquiler, ya que gran parte del proceso constructivo se llevó a cabo en las costas (Valenzuela, 2008; Rullán, 2008). Durante los últimos años se viene insistiendo en la necesidad de realizar "una profunda renovación de las estructuras" (Vera y Baños, 2010: 350), pues la oferta de sol y playa demanda, cada vez más, una apuesta por la calidad y por la diversidad de actividades que favorezcan la autorrealización del turista (Salvà, 2011), sin olvidar la riqueza patrimonial del traspaís o zona de influencia con el interior. Por su parte, el "turismo de interior", articulado en todas sus modalidades desde los años noventa del siglo pasado, se viene desarrollando como un sector cada vez más maduro, suma de modalidades y fórmulas donde coexisten productos tradicionales ligados al medio natural, rural y urbano, junto a otros espacios emergentes, donde comienza a producirse, también, en estos espacios alternativos al turismo de costa, efectos masivos sobre determinados espacios sensibles, de fácil alteración ambiental (Díez, 2012). Por este motivo, parece necesario profundizar en un esfuerzo en clave de sostenibilidad local, con fuertes medidas de capacidad de carga (Cañizares, 2013: 88) o lo que es lo mismo de control del número de visitantes, lo que obliga a seguir trabajando en pos de la identidad a partir de "modelos de bajo impacto ambiental", persiguiendo al mismo tiempo, en esta etapa de crisis, lograr generar empleo, rentas y servicios (Vázquez y Martín, 2011: 171). La información on-line se ha convertido en la 
principal fuente de datos a la hora de elegir destino, a pesar de sus limitaciones y puntos débiles en la promoción turística (Villalba et al., 2014), pues muchos espacios turísticos se encuentran en zonas claramente periféricas y de difícil acceso.

Las tipología de "espacios de turismo de interior" se puede agrupar en cuatro espacios: en primer lugar, el "turismo de naturaleza", el más vulnerable, pues afecta, especialmente, a un turismo natural o ecoturismo centrado en espacios protegidos (Parques Nacionales, Parques Naturales, etc.) donde deben de ser inflexibles las bases de la sostenibilidad, la integridad y la endogeneidad (Antón et al., 2008), aspectos, todos ellos, que podrían verse perjudicados debido al elevado número de turistas que los visitan, sin olvidar la amenaza existente de querer introducir la caza o actividad cinegética en dichos espacios. El "turismo urbano" está sufriendo el acoso de los visitantes, especialmente en las Ciudades Patrimonio de la Humanidad (Troitiño y Troitiño, 2009), pues su belleza y singularidad ofrecen claros elementos de fragilidad para su conservación (Zárate, 2012), a dichos núcleos se añadirían las ciudades histórico-artísticas y los parques arqueológicos. El "turismo rural" se ha desarrollado desde un planteamiento más territorial, debido a la influencia de la experiencia comunitaria europea de Desarrollo Rural LEADER, llevando a cabo una apuesta por la diversidad e identidad cultural (Cànoves et al., 2014); a la vez que origina una amplia gama de alojamientos, rutas turísticas y gastronomía popular, sin olvidar la preocupación por la sostenibilidad y la rentabilidad social (Cebrián, 2008). Y por último, el "turismo industrial" donde se valorizan los monumentos industriales, así como los territorios de la industria, convertidos en patrimonio cultural de indudable interés (Pardo, 2011); un lugar destacado lo ocupa el patrimonio minero o patrimonio mineroindustrial del que nos habla Cañizares (2011: 137) cuando hace referencia a la musealización de la propia mina o la reconversión/rehabilitación de los elementos materiales para otros usos de carácter cultural, salvando de esta forma "una parte del patrimonio que aún no ha desaparecido y ponerlo al servicio de

Figura $\mathrm{N}^{\circ} 1$

Los espacios del turismo en España

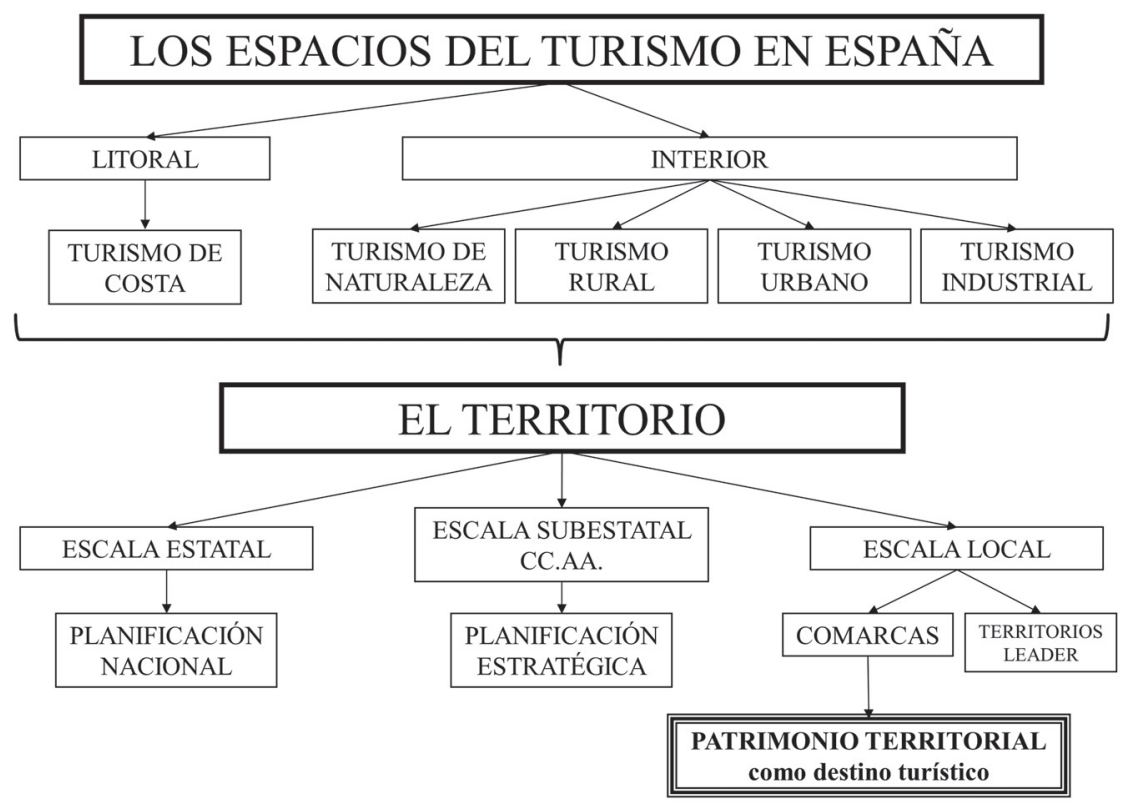

Fuente: Elaboración propia. 
la población". La Planificación Nacional del Turismo junto a la Planificación Estratégica de las Comunidades Autónomas (CCAA), velan o deben velar por el desarrollo de los espacios del turismo en España.

\section{El patrimonio territorial o comarcal}

De la misma forma que Pearce (2014: 29) ha puesto en relación los territorios con el turismo "desde una perspectiva basada más en lo territorial, usando conceptos como espacio turístico o lugar turístico, para referirse a elementos territoriales transformados por el turismo"; otros autores han relacionado el territorio con el patrimonio, al considerar el patrimonio territorial como recurso cultural y económico de primer orden (Ortega Valcárcel, 1998: 47); o bien cuando se ha hecho mención al patrimonio natural y territorial y en concreto al territorio "poco a poco todo el territorio se ha ido convirtiendo en objeto de atención y de protección... El territorio puede considerarse un patrimonio natural y cultural heredado, construido durante siglos por el hombre", tal y como ha indicado Horacio Capel (2014: 73), para a continuación, hacer referencia al patrimonio del medio rural, al patrimonio minero, litoral, marítimo y fluvial.

Los territorios supramunicipales más populares en España son sin lugar a dudas las comarcas, de carácter natural-cultural, únicas e irrepetibles (Feria, 2010; Silva y Fernández, 2008), destacando su cabecera comarcal. Parece lógico, que sin fraccionar el territorio, la comarca en su conjunto pudiera ser considerada como Patrimonio Territorial, objeto de interés turístico (Pillet, 2012b), analizada de forma integral, valorando los elementos materiales o tangibles, a la vez que los elementos inmateriales o intangibles (Olivera, 2011: 667). Territorios que podrían relacionarse con los microespacios de los que habla Hiernaux (2008: 5): "el turismo es antes que todo una práctica sociocultural en microespacios".

Aunque la Comarcalización en España es muy desigual, pues afecta de distinta forma a las Comunidades Autónomas ${ }^{17}$, algunos

\footnotetext{
17 En España solo dos Comunidades Autónomas han aprobado, siguiendo su Estatuto de Autonomía, la comarcalización política: Aragón y Cataluña. Las
}

Gobiernos regionales vienen utilizando las comarcas con fines turísticos, como así se ha podido comprobar en los folletos ofrecidos en la Feria Internacional del Turismo (FITUR) del presente año 2015, donde mientras Cataluña y Galicia agrupan comarcas ofreciendo un producto turístico nuevo, otras regiones las presentan de forma aisladas o bien combinando comarcas con destinos consolidados. Con la Ley de Organización Comarcal de Cataluña (1987) se consolidaron un total de 41 comarcas, con escaso poder territorial. La Generalitat de Catalunya o Gobierno de Cataluña ha transformado, para su utilización turística, las 41 comarcas en nueve "Marcas Turísticas"18, como resultado de la agrupación de la totalidad de sus comarcas, aspecto que ha sido citado por Corral y Cànoves (2013: 61). El Gobierno de Aragón, con su Ley de Comarcalización (1993) programó un total de 33 comarcas, 8 de ellas ${ }^{19}$ son ofertadas dentro de las tres provincias, como destinos turísticos. La Xunta de Galicia, aunque aprobó oficialmente su mapa comarcal, luego no se llevó a cabo la comarcalización. A partir del dicho mapa, reagrupando comarcas, en la actualidad la Xunta ofrece 14 Geodestinos $^{20}$. El Gobierno de La Rioja, que no cuenta con división comarcal oficial, ha lanzado una oferta turística basada en las cabeceras de comarcas ${ }^{21}$. El Gobierno

restantes comunidades hacen referencia a comarcas funcionales o urbanas (heterogéneas) y a comarcas geográficas o humanas (homogéneas).

18 Generalitat de Catalunya, Agencia Catalana de Turismo (2013). Marcas Turísticas: Barcelona, Costa Barcelona, Paisatges Barcelona, Costa Brava, Costa Daurada, Terres de l'Ebre, Terres de Lleida, Pirineus, Val d'Aran,

${ }^{19}$ Gobierno de Aragón: Aragón (Huesca / Es mágica. Teruel / Te sorprenderá. Zaragoza / La encrucijada). Comarcas ofertadas para el turismo en Teruel: Sierra de Albarracín, Maestrazgo, Matarraña, Jiloca y Bajo Aragón. En Hueca: Sograrbe-Ribagorza, Los Monegros y Somontano. Y en Zaragoza: Cinco Villas.

20 Xunta de Galicia (2013): "Galicia. Mapa turístico". Geodestinos: Rías Altas, Costa da Morte, Terras de Santiago, Mariña Lucense, Lugo e a Terra Chà, Ancares-Courel, Ribeira Sacra, O Ribeiro, Terras de Ourense e Allariz, Celanova-Limia, Verín-Viana, Manzaneda-Trevinca, Rías Baixas, y por último Deza-Tabeirós.

21 Gobierno de La Rioja (2014) "La Rioja Apetece". Cabeceras de comarcas: Alfaro, Calahorra, Ezcaray, Haro, Logroño, Los Cameros, Nájera, San Millán de la Cogolla, Santo Domingo de la Calzada, y Valle de Cidacos 
de Navarra ha partido de su tradicional comarcalización geográfica para presentar una zonificación turística que divide a la región en cuatro destinos turísticos ${ }^{22}$. El Gobierno de Murcia ofrece un "mapa turístico" donde destaca cuatro comarcas de carácter rural ${ }^{23}$, mientras el resto de la región lo conforman núcleos urbanos consolidados. La Generalitat Valenciana publicó una Propuesta de Demarcaciones Territoriales Homologadas (1987) o comarcas, gestión ${ }^{24}$ que ha sido cedida a los Patronatos Provinciales de Turismo, donde solo dos de las tres provincias, Alicante y Valencia, han desarrollado la comarcalización como oferta turística. Y el Gobierno de Extremadura ha confiado esta tarea a la Red Extremeña de Desarrollo Rural (REDEX) lo que ha originado la elaboración de un "Mapa turístico comarcal. Extremadura Rural" 25 quedando excluidos los núcleos de carácter urbano.

Las restantes Comunidades Autónomas, especialmente las integradas en la península,

http://lariojaturismo.com/comunidad/larioja/folletos/ categoria/por-comarcas/b9aaf7ad-a4cb-46de-a1 ef830360c79ec1

22 Gobierno de Navarra (2014) "Reyno de Navarra". Comarcas: Los Pirineos, La Cuenca de Pamplona, La Zona Media y La Ribera.

${ }^{23}$ Región de Murcia "Costa Cálida. Mapa turístico" Comarcas: Nordeste, Noroeste, Sierra Espuña, y Valle de Ricote y Cieza.

${ }^{24}$ Generalitat Valenciana (2013) "Oferta turística municipal y comarcal de la Comunitat Valenciana" http://www.turisme.gva.es/turisme/es/files/pdf/observatorio/anuarios/Oferta2013-def.pdf. La provincia de Castellón no oferta su estructura comarcal para el turismo, sí lo hacen Alicante y Valencia. En Alicante: El Comtat, La Marina Alta, La Marina Baixa, L'Alcoià, Alto Vinalopó, Medio Venalopó, Bajo Vinalopó, L'Alacantí, La Vega Baja. En Valencia: Rincón de Ademuz, La Serranía, El Campo del Turia, El Camp de Morvedre, L'Horta, Requena-Utiel, La Hoya de Buñol-Chiva, Valle de Ayora Cofrentes, La Ribera Alta, La Ribera Baixa, La Canal de Navarrés, La Costera, La Vall d'Albaida, La Safor.

${ }^{25}$ Red Extremeña de Desarrollo Rural (REDEX) Mapa turístico comarcal. Extremadura Rural. http://www. redex.org/index. php?s=turismodoc $\& i d=139$. Comarcas en Cáceres: Sierra de Gata, Las Hurdes, Trasierra-Tierras de Granadilla, Valle del Ambroz, Valle del Jerte, La Vera, Campo Arañuelo, Villuercas Inores Jara, Tajo-Salor-Almote, Miajas-Trujillo, Sierra de Montanchez y Tamuja, Valle del Alagón y por último, Sierra de San Pedro-Los Baldíos. Por su parte en Badajoz: Lácara, La Liberia, Vegas Altas del Guadiana, La Serena, Sierra Grande-Tierra de Barros, Campiña Sur, Tentudía, Sierra Suroeste, Zafra-Río Bodión, y Olivenza. no han llevado a cabo una oferta turística comarcal $^{26}$. Parece lógico que estas marcas turísticas y geodestinos, resultado de la agrupación de comarcas, así como las unidades comarcales, resultado de una larga tradición popular, puedan ser consideradas como Patrimonio Territorial, objeto de interés turístico.

Los territorios, en este caso comarcales, están integrados por paisajes, como parte del territorio, siendo el paisaje un elemento fundamental del turismo: "el paisaje constituye hoy un importante recurso turístico... la calidad del paisaje se debería mostrar siempre como factor determinante en el proceso de elección del destino turístico", como señala Espejo (2011: 442 y 459). Rafael Mata ha afirmado que "la proximidad semántica y geográfica entre comarca y paisaje adquiere hoy además un significado estratégico importante, al considerarse el paisaje como patrimonio y recurso que actúa o puede actuar como elemento de identidad, de marca, de atracción y de competitividad del territorio comarcal" haciendo mención también a la vieja tradición de la imagen literaria del paisaje (Mata, 2011: 12).

La literatura de viajes ha recogido algunas obras donde la comarca ha tenido un valor central o principal, la más conocida universalmente es sin duda la gran comarca de La Mancha, debido a la estrecha relación que ha tenido con El Quijote, lo que ha permitido conocer la opinión, a lo largo de cuatro siglos, de cuantos la visitaron, tanto de paso, como los que siguieron los caminos del genial aventurero (Pillet, 2015b). Junto a ella destacaremos, entre otras, dos ejemplos significativos, publicadas ambas en los años cuarenta del pasado siglo. La primera la protagonizó un escritor de viajes que se decantó claramente por "lo local sobre lo universal" (Arroyo, 2007: 394), nos referimos a Josep Pla en su "Viaje en autobús" (1942) donde considera el viajar como un "cambio de aires". Tras recorrer su provincia (Gerona o Girona) llegará a la comarca costera de "La Maresma" o Maresme: "la falda de tierra que cae dulcemente hasta el mar desde estos montes

\footnotetext{
26 Asturias, Cantabria, Castilla y León, Castilla-La Mancha, Madrid y País Vasco.
} 
de perfil tan dulce, sobre los que recortan, a la hora del crepúsculo, las siluetas de unos pinos y en los que anidan estos pueblos recoletos". En segundo lugar, el Premio Nobel Camilo José Cela emprendería su "Viaje a la Alcarria", para volverlo a realizar cuarenta años después (1946-1986) por aquel "hermoso país" poco visitado donde se puede contemplar, entre exageraciones, los cambios producidos que detectaría "el viajero" como así gusta denominarse. Recorrido realizado a lo largo de la comarca de La Alcarria de Guadalajara, como más próxima a Madrid, olvidando la Alcarria de Cuenca (Pillet, 2011).

\section{Conclusión}

Tras el análisis de las distintas escalas del espacio geográfico, la escala estatal y subestatal, y especialmente esta última, se convierte en el marco de análisis del turismo, una de las temáticas de mayor actualidad e interés tanto geográfico como social. Los tiempos del turismo vinieron precedidos de distintos viajeros que convirtieron sus saberes, tanto estratégico, formativo y estético, en el precedente del turismo, especialmente con el "Grand Tour" y con el "Tour Románti$\mathrm{CO}^{\prime \prime}$, dando como resultado la evolución del paisaje literario, a partir de la literatura de viajes.

En los espacios del turismo, tanto de costa como de interior (de naturaleza, rural, urbano e industrial) parece conveniente reivindicar como destino turístico el desarrollo de un turismo territorial o comarcal, que contemple en su conjunto la riqueza microespacial, pudiendo ser considerada también como Patrimonio Territorial. Un patrimonio basado en las unidades comarcales o agrupaciones comarcales, por ser los territorios más populares, mezcla de elementos naturales y culturales, materiales e inmateriales, y de contenidos literarios, algunas veces, con el fin de motivar el deseo de viajar o de hacer turismo local.

\section{Referencias bibliográficas}

ALMEIDA GRACÍA, F. La política turística en España y Portugal. Cuadernos de Turismo, 2012, No 30, p. 9-34.
ANTÓN, S.; BLAY, J. y SALVAT, J. Turismo, actividades recreativas y uso público en los parques naturales. Propuesta para la conservación de los valores ambientales y el desarrollo productivo local. Boletín de la Asociación de Geógrafos Españoles, 2008, № 48, p. 5-38.

ARROYO ILERA, F. Josep Pla y las Guías de España de Ediciones Destino: Una perspectiva geoturística y literaria de España a mediados del siglo XX. En: PAÜL, V. y TORT, J. Territorios, paisajes y lugares. Trabajos recientes de pensamiento geográfico. Madrid: Galerada y AGE, 2007, p. 389-404.

BATTUTA, I. A través del Islam. Madrid: Editora Nacional, 1981.

BOURGOING, J-F. Imagen de la moderna España. Alicante: Universidad de Alicante, 2012.

BOWLES, P. Desafío a la identidad. Viajes 1950-1993. Barcelona: Galaxia Gutenberg, 2013.

BURGUEÑO, J. La invención de las provincias. Madrid: Catarata, 2011.

BURGUEÑO, J. y GUERRERO, M. EI mapa municipal de España. Una caracterización geográfica. Boletín de la Asociación de Geógrafos Españoles, 2014, № 64, p. 11-36.

CAMBA, J. Crónicas de viaje. Impresiones de un corresponsal español. Madrid: Fórcola, 2014.

CÀNOVES, G.; VILLARINO, M.; BLANCO-ROMERO, A.; DE UÑA, E. y ESPEJO, C. (editores). Turismo de interior: renovarse o morir. Estrategias y productos en Cataluña, Galicia y Murcia. Valencia: Universitat de València, 2014.

CAÑIZARES RUIZ, M.C. Patrimonio, Parques Mineros y Turismo en España. Cuadernos de Turismo, 2011, N²7, p. 133-153.

CAÑIZARES RUIZ, M.C. Sostenibilidad y turismo: De la documentación internacional a la planificación en España < Horizonte 2020>. Boletín de la Asociación de Geógrafos Españoles, 2013, № 61, p. 67-92. 
CAPEL, H. El patrimonio: la construcción del pasado y del futuro. Barcelona: Ediciones del Serbal, 2014.

CARLOS, A.F.A. Crisis y superación en el ámbito de la Geografía crítica: construyendo la metageografía. Revista de Geografía Norte Grande, 2012, № 51, p. 5-19.

CASTAÑO, F. El despilfarro. La sangría de la España autonómica. Madrid: Espasa. 2011.

CEBRIÁN ABELLÁN, F. (coordinador). Turismo rural y desarrollo local. Cuenca: Universidad de Castilla-La Mancha, 2008.

CELA, C.J. Viaje a la Alcarria. Madrid: Espasa-Calpe, 1970.

CELA, C.J. Nuevo viaje a la Alcarria. Barcelona: Plaza\&Janes, 1986.

COLÓN, C. Los cuatro viajes. Testamento. Madrid: Alianza, 1986.

CORRAL, J.A. y CÀNOVES, G. La investigación turística publicada en revistas turísticas y no turísticas: análisis bibliométrico de la producción de las universidades catalanas. Cuadernos de Turismo, 2013, № 31, p. 5581.

CORRAL, J.A. y DE SAN EUGENIO, J. La investigación de la Geografía del Turismo en España a través del análisis bibliográfico de las actas del Coloquio de Geografía del Turismo, Ocio y Recreación (1990-2012). Boletín de la Asociación de Geógrafos Españoles, 2013, No63, p. 535-549.

CROTTI, R. El lugar que prefieren los viajeros. Diario El País, 7 de mayo de 2015.

DARWIN, CH.R. Viaje de un naturalista alrededor del mundo. Madrid: Grech, 1989.

DE HUMBOLDT, A. Del Orinoco al Amazonas. Viaje a las regiones equinocciales del nuevo continente. Barcelona, Labor, 1962.

DICKENS, CH. El viajero sin propósito. Madrid: Gadir, 2014.

DÍEZ SANTOS, D. Los turismos de interior: un enfoque desde la dimensión de las modalidades turístico-recreativas. Documents d'Anàlisi Geogràfica, 2012, Vol. 58, № 3, p. 373-396.

DONAIRE, J.A. Turismo cultural. Entre la experiencia y el ritual. Girona: Vitella. 2012.

DWYER, L.; GILL, A. \& SEETARAM, N. Handbook of Research Methods in Tourism, Quantitative and Qualitative Approaches. Cheltenham-Northampton: Edward Elgar, 2012.

ESPEJO MARÍN, C. El paisaje como recurso turístico. En: SIMANCAS, M.R. y CORTINA, A. (coordinadores). Retos y perspectivas de la gestión del paisaje de Canarias. Las Palmas de Gran Canaria: Gobierno de Canarias y Universidad Internacional Menéndez Pelayo, 2011, p. 439-461.

ESTRABÓN. Geografía. Madrid: Gredos, 5 Vol., 1991 y ss,

FERIA TORIBIO, J.M. Patrimonio territorial y desarrollo sostenible: un estudio comparativo en Iberoámerica y España. Estudios Geográficos, 2010, № 268, p. 129-159.

FERNÁNDEZ, A.; PEDREGAL, B.; RODRÍGEZ, J.C.; PITA, M.F. y ZOIDO, F. El concepto de cohesión territorial. Escalas de aplicación, sistemas de medición y políticas derivadas. Boletín de la Asociación de Geógrafos Españoles, 2009, № 50, p.157-172.

FERNÁNDEZ, A.; GARCÍA, M. e IVARS, J.A. (coordinadores). La investigación de la Geografía del Turismo en las Comunidades Autónomas españolas. Orígenes, desarrollo y perspectivas de una disciplina en el horizonte de la Geografía. Madrid: Asociación de Geógrafos Españoles, 2010.

FORD, R. Manual para viajeros por España y lectores en casa. Madrid: Turner, 7 Vol. 2008.

GARCÍA RUIZ, J.M. Las citas internacionales de las revistas españolas de Geografía. Boletín de la Asociación de Geógrafos Españoles, 2008, No 46, p. 207-225.

GARCÍA, J.C.; MICHELINI, J.J. y MÍNGUEZ, M.C. La presencia de la geografía 
iberoamericana en las revistas científicas españolas, Biblio 3W, 2009, Vol. XIV, No 845. Disponible en Internet: http://www.ub.edu/ geocrit/b3w-845.htm

GOETHE, J.W. Viaje á Italia. Madrid: Librería Viuda de Hernando, 2 tomos, 1891.

GÓMEZ ESPELOSÍN, F.J. El descubrimiento del mundo. Geografía y viajeros en la antigua Grecia. Madrid: Akal, 2000.

GONZÁLEZ, S. La geografía escalar del capitalismo actual. Scripta Nova. Revista de Geografía y Ciencias Sociales, 2005, Vol. IX, $N^{\circ}$ 189. Disponible en Internet:

http://www.ub.edu/geocrit/sn/sn-189.htm

HARVEY, D. Espacios del capital. Hacia una geografía crítica. Madrid: Akal, 2007.

HEMINGWAY, E. París era una fiesta. Madrid: Seix Barral, 2001.

HERÓDOTO. Historias. Madrid: Consejo Superior de Investigaciones Científicas, 2 Vol., 1990.

HIERNAUX, D. Una década de cambios: La Geografía Humana y el estudio del turismo. Scripta Nova. Revista de Geografía y Ciencias Sociales, 2008, Vol. XII, № 270 (87). Disponible en Internet: http://www.ub.es/ geocrit/sn/sn-270/sn-270-87.htm

JENNINGS, G.R. Qualitative researrch: its nature and evolution. In: DWYER, L.; GILL, A. \& SEETARAM, N. Handbook of Research Methods in Tourism, Quantitative and Qualitative Approaches. Cheltenham-Northampton: Edward Elgar, 2012, p. 309-323.

KAPUSCINSKI, R. Viajes con Heródoto. Barcelona: Anagrama, 2006.

LACOSTE, Y. ¿Por qué Hérodote? Crisis de la geografía y geografía de la crisis. En: LACOSTE, Y.; SANTIBÁÑEZ, R.; VARLIN, T. y GIBLIN, B. Geografías, ideologías, estratégias espaciales. Madrid: Dédalo, 1977, p. 25-66.

LASANTA, T. y MARTÍN VIDE, J. (coordinadores). La Investigación Geográfica en España (1990-2012). Madrid: Asociación de Geógrafos Españoles, 2013. Disponible en
Internet: http://www.age-geografia.es/gestion/ uploads/Investigacion_Geogr.pdf

LINDÓN, A. y HIERNAUX, D. (directores). Los giros de la geografía humana. Desafíos y horizontes. Barcelona: Anthropos, 2010.

LOIS GONZÁLEZ, R.C. Turismo y territorio a principios del siglo XXI. Una reflexión geográfica desde el ámbito de la gestión pública. En: TROITIÑO, M.A; GARCÍA, J.S. y GARCÍA, M. (coordinadores). Destinos turísticos: viejos problemas ¿nuevas soluciones? Cuenca: Universidad de Castilla-La Mancha, 2008, p. 23-47.

LÓPEZ ONTIVEROS, A. Caracterización geográfica de Andalucía según la literatura viajera de los siglos XVIII y XIX. Ería, 2001, No 54-55, p. 7-51.

LLEDÓ, J. Grand Tour: El viaje durante la Ilustración y el romanticismo. En: COLINAS, A. y LLEDÓ, J. Grand Tour. Viaje a Italia. Madrid: Circulo de Lectores, 2000, p. 113-139.

MACZAK, A. Viajes y viajeros en la Europa Moderna. Barcelona: Omega, 1996.

MAGRIS, C. El infinito viajar. Barcelona: Anagrama, 2008.

MATA OLMO, R. Introducción. El sentido y los objetivos de un Atlas de los paisajes de Castilla-La Mancha. En: PONS, B. (director). Atlas de los Paisajes de Castilla-La Mancha, Cuenca: Ediciones de la Universidad de Castilla-La Mancha, 2011, p. 11-19.

MATURANA, F.R. y ARENAS, F. El policentrismo en Chile: medición exploratoria para el sistema de ciudades de las regiones de La Araucanía, de Los Ríos y de Los Lagos. Revista de Geografía Norte Grande, 2012, No 52 , p. 37-56.

MENDIZÁBAL, E. ¿Hay alguna geografía histórica humana que no sea geografía histórica? Revista de Geografía Norte Grande, 2013, No 54, p. 31-49.

DE MONTAIGNE, M. Diario de viaje a Italia por Suiza y Alemania en 1580 y 1581. Madrid: Cátedra, 2010. 
MORENO, S. y PICAZO, P. Difusión de la investigación científica en revistas de turismo realizada por instituciones españolas. Revista de Análisis Turístico, 2012, No 14, p. 33-52.

MOUREAU, F. Viajar por Europa en el Siglo de las Luces. En: ROMERO, L. y ALMARCEGUI, P. (coordinadores). Los libros de viaje: realidad vivida y género literario. Madrid: Akal, 2005, p. 25-47.

OLIVERA, A. Patrimonio inmaterial, recurso turístico y espíritu de los territorios. Cuadernos de Turismo, 2011, No 27, p. 663-677.

ORTAS DURÁN, E. La España de los viajeros (1755-1846): Imágenes reales, literaturizadas, soñadas. En: ROMERO, L. y ALMARCEGUI, P. (coordinadores). Los libros de viaje: realidad vivida y género literario. Madrid: Akal, 2005, p. 48-91.

ORTEGA CANTERO, N. La imagen literaria del paisaje de España. En: MATA, R. y SANZ, C. Atlas de los paisajes de España. Madrid: Ministerio de Medio Ambiente, 2003, p. 30-52.

ORTEGA, E.; RODRÍGUEZ, B. y SUCH, M.J. Las tesis doctorales de turismo en España. 2000-2012. Estudios Turísticos, 2013, No 195, p. 9-31.

ORTEGA VALCÁRCEL, J. El patrimonio territorial: el territorio como recurso cultural $y$ económico. Ciudades, 1998, № 4, p. 33-48.

PARDO ABAD, C.J. Paisajes industriales e industrias para el turismo: simbolismo patrimonial y alcance territorial. Rotur. Revista de ocio y turismo, 2011, No 4 . Disponible en Internet: http://www.rotur.es/index.php/rotur/ article/view/28

PEARCE, D. Destinos Turísticos: conceptos e implicaciones para su gestión en tiempos de cambio. En: LÓPEZ PALOMEQUE, F. y CÀNOVES VALIENTE, G. Turismo y Territorio. Innovación, renovación y desafíos. Valencia: Tirant Humanidades, 2014, p. 21-34.

PHILLIMORE, J. \& GOODSON, L. Qualitative research in tourism. Ontologies, apistemologies and methodologies. London-New York: Routledge, 2004.
PILLET CAPDEPÓN, F. Espacio y ciencia del territorio. Proceso y relación global-local. Madrid: Biblioteca Nueva, 2008.

PILLET CAPDEPÓN, F. Los viajes de Cela por La Alcarria. En: PONS, B. (director). Atlas de los Paisajes de Castilla-La Mancha. Cuenca: Ediciones de la Universidad de Castilla-La Mancha, 2011, p. 50-51.

PILLET CAPDEPÓN, F. Planificación Territorial. Propiedad y Valoración Catastral (España 1750-2010). Madrid: Biblioteca Nueva, 2012a.

PILLET CAPDEPÓN, F. El turismo de interior en la España peninsular: el patrimonio territorial como destino turístico. Boletín de la Asociación de Geógrafos Españoles, 2012b, $\mathrm{N}^{\circ} 59$, p. 345-366.

PILLET CAPDEPÓN, F. El paisaje literario y su relación con el turismo cultural. Cuadernos de Turismo, 2014, No 33, p. 297-309.

PILLET CAPDEPÓN, F. La evolución de la imagen literaria del paisaje urbano: de la ciudad moderna a la ciudad actual. Estudios Geográficos, 2015a, № 278, p. 285-307.

PILLET CAPDEPÓN, F. El Quijote y La Mancha: la evolución de la imagen literaria del paisaje rural. Biblio 3W, 2015b, Vol. XX, $N^{\circ} 111$. Disponible en Internet: http://www.ub.edu/geocrit/b3w-1112.htm

PILLET, F.; CAÑIZARES, M.C.; RUIZ, Á.R.; MARTÍNEZ, H.S.; PLAZA, J.J.; y SANTOS, J.F. Applying the European Spatial Development Perspective in Low-density Regions: A Methodology Based on Mobility and Labour Market Structure. Urban Studies, 2014, Vol. 51, No3, p. 577-595.

PLA, J. Viaje en autobús. Barcelona: Austral, 2015.

POLO, M. Libro de las cosas maravillosas. Barcelona: ABC, 2004.

RACIONERO, L. y RACIONERO, A. El ansia de vagar. Barcelona: RBA, 2013.

REBOK, S. y FERNÁNDEZ, M. Alexander von Humboldt: su estancia en España y su 
gran expedición americana. Enlaces, 2006, $\mathrm{N}^{\circ}$ 5. Disponible en Internet: http://www. cesfelipesegundo.com/revista/articulos2006/ art05.pdf

RULLÁN SALAMANCA, O. Reconversión y crecimiento de las zonas turísticas. Del fordismo al postfordismo. En: TROITIÑO, M.A; GARCÍA, J.S. y GARCÍA, M. (coordinadores). Destinos turísticos: viejos problemas, ¿nuevas soluciones? Cuenca: Universidad de CastillaLa Mancha, 2008, p. 587-624.

SALVÀ TOMÁS, P.A. El turismo residencial ¿Una manifestación de nuevos turismos y nuevos comportamientos turísticos en el siglo XXI? Cuadernos de Turismo, 2011, № 27, p. 823-836.

SILVA, R. y FERNÁNDEZ, V. El Patrimonio y el Territorio como activos para el desarrollo desde la perspectiva del ocio y del turismo. Investigaciones Geográficas, 2008, № 46, p. 69-88.

SILVEIRA, M.L. Tiempo y espacio en geografía: dilemas y reflexiones. Revista de Geografía Norte Grande, 2013, № 54, p. 9-29.

TONWNSEND, J. Viaje por España en la época de Carlos III (1786-1787). Madrid: Turner, 1988.

TRIBE, J. Knowing about tourism: epistemological issues. In: PHILLIMORE, J. \& GOODSON, L. Qualitative research in tourism. Ontologies, apistemologies and methodologies. London/New York: Routledge, 2004, p. 46-62.

TROITIÑO, M.A. y TROITIÑO, L. Turismo cultural y destinos patrimoniales en España: situación actual y retos de futuro. En: MONDEJAR, J.A. y GÓMEZ, M. (coordinadores). Turismo cultural en ciudades Patrimonio de la Humanidad. Cuenca: Universidad de CastillaLa Mancha, 2009, p. 15-51.

UREÑA, J.M.; PILLET, F. y MARMOLEJO, C. Aglomeraciones/regiones urbanas basadas en varios centros: planificación. Ciudad y Territorio. Estudios Territoriales, 2013, № 176, p. 249-266.
VALENZUELA RUBIO, M. Nuevos turismos para nuevos turistas. De la identificación a la captación de la clientela. En: CEBRIÁN ABELLÁN, F. (coordinadores). Turismo rural y desarrollo local. Cuenca: Universidad de Castilla-La Mancha, 2008, p. 57-65.

VÁZQUEZ, C. y MARTÍN, F. Problemas de sostenibilidad del turismo rural en España. Anales de Geografía de la Universidad Complutense, 2011, Vol. 31, №1, p. 171-194.

VERA, J.F. (coordinador). Análisis territorial del turismo y planificación de destinos turísticos, Valencia: Tirant lo Blanch, 2011.

VERA, J.F. y BAÑOS, C.J. Renovación y reestructuración de los destinos turísticos consolidados del litoral: las prácticas recreativas en la evolución del espacio turístico. Boletín de la Asociación de Geógrafos Españoles, 2010, No 53, p. 329-353.

VILLALBA, R.; MARTÍNEZ, L. y MARTÍNEZ, S.M. Análisis regional de las empresas turísticas on-line en España. Cuadernos de Turismo, 2014, No 34, p. 335-349.

ZÁRATE MARTÍN, M.A. Paisaje, forma y turismo en ciudades históricas. Estudios Geográficos, 2012, № 273, p. 657-694.

ZOIDO NARANJO, F. Territorio y paisaje, conocimiento, estrategias y políticas. En: PILLET, F.; CAÑIZARES, M.C. y RUIZ, A.R. (editores). Territorio, paisaje y sostenibilidad. Un mundo cambiante. Barcelona: Ediciones del Serbal, 2010, p. 87-114.

ZUSMAN, P. La geografía histórica, la imaginación y los imaginarios geográficos. Revista de Geografía Norte Grande, 2013, No 54, p. 51-66. 
